\title{
Artigos
}

\section{EVENTO FIM DE DÉCADA: PERFORMER, ESPECTADOR E ESPAÇO PÚBLICO ENTRE A DITADURA E A DEMOCRACIA}

EVENTO FIM DE DÉCADA: PERFORMER, SPECTATOR, AND PUBLIC SPACE BETWEEN DICTATORSHIP AND DEMOCRACY

\section{EVENTO FIM DE DÉCADA: PERFORMER, ESPECTADOR $Y$ ESPACIO PÚBLICO ENTRE LA DICTADURA Y LA DEMOCRACIA}

\section{Patricia Morales Bertucci}

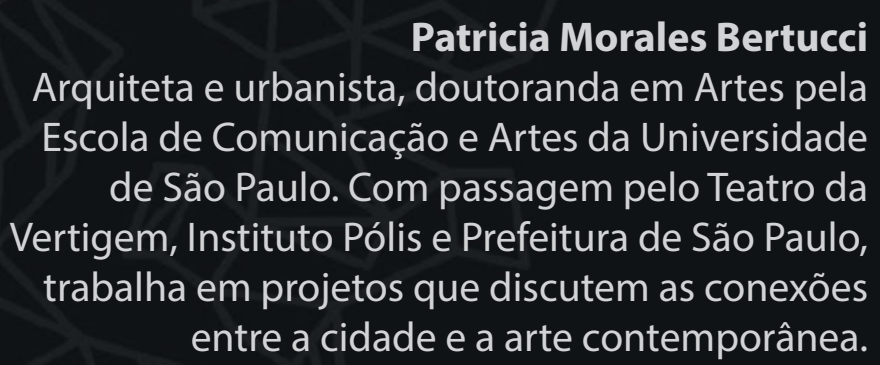




\section{Resumo}

Nos últimos anos da ditadura militar, entre o fim dos anos de 1970 e início de 1980, as manifestações populares e artísticas voltavam às ruas da cidade de São Paulo. Como parte desse movimento, o Evento Fim de Década (1979) foi um acontecimento no qual os coletivos de arte independente ocuparam a Praça da Sé e convidaram os transeuntes não para serem seus espectadores, mas responsáveis diretos pela construção de situações criativas, novas possibilidades relacionais, corporais e contextuais nos espaços públicos já com ares democráticos.

Palavras-chave: Arte urbana, Intervenção urbana, Performance urbana, Produção do espaço, Urbanismo.

\section{Abstract}

In the last years of the military dictatorship, which occurred from the end of the 1970s to the beginning of the 1980s, popular and artistic events returned to the streets of São Paulo. As part of this movement, the Evento Fim de Década (1979) is an event in which independent art collectives occupied the Praça da Sé (Cathedral Square) and invited passers-by, not to be their audience, but to be directly responsible for the construction of creative situations, of new relational, corporal and contextual possibilities in public spaces already filled with democratic air.

Keywords: Production of space, Urban art, Urban intervention, Urban performance, Urban design.

\section{Resumen}

En los últimos años de dictadura militar brasileña, entre los años 1970 y 1980, eventos populares y artísticos regresaron a las calles de São Paulo. Como parte de este movimiento, el Evento Fim de Década (1979) es un evento en el que los colectivos de arte independientes ocuparon la Praça da Sé, y se les invitaban a los transeúntes a no ser su público, sino directamente responsables de la construcción de situaciones creativas, nuevas posibilidades relacionales, corporales y contextuales, en los espacios públicos ya con el inicio del regreso de la democracia.

Palabras clave: Arte urbana, Intervención urbana, Performance urbana, Producción de espacio, Urbanismo. 
Em setembro de 1979, o Viajou Sem Passaporte convocou cerca de 36 pessoas, a maioria dos coletivos de arte independente, para uma reunião no seu atelier, localizado na Rua Caio Graco, na Lapa. Seu objetivo foi discutir a organização do Evento Fim de Década, uma performance urbana que ocupou por um dia a Praça da Sé, além de outros pontos da cidade de São Paulo, durante três meses consecutivos, com os pré-eventos. Tais intervenções interromperam o cotidiano da cidade que passava por um momento de grande importância política, marcado pelo retorno dos artistas às ruas, junto com os movimentos sociais e as festas populares, tendo em vista que a ditadura militar caminhava para seu fim, na virada da década de 1970 para a de 1980.

O Viajou Sem Passaporte surgiu em maio de 1978 e teve intensa atuação até 1982, composto por oito estudantes das áreas de artes cênicas, cinema, música e jornalismo da Escola de Comunicações e Artes da Universidade de São Paulo: Beatriz Caldano, Celso Santiago, Carlos Alberto Gordon, Luiz Sergio Ragnole Silva (Raghy), Marli de Souza, Márcia Meirelles, Marilda Carvalho, Roberto Mello. O primeiro trabalho do coletivo foi no Teatro Eugênio Kusnet, depois iniciaram uma série de intervenções urbanas e, por fim, passaram a invadir espetáculos teatrais de outros grupos, sem aviso prévio. Em paralelo também produziram publicações, como a USBAEAE e a WYK, que tratavam em geral de questões estético-políticas. Desde o princípio, o Viajou Sem Passaporte buscou instaurar crises na normalidade, com forte influência surrealista, eles colocaram no lugar de "obra de arte" a denominação "trabalho de arte": "não criamos produtos para serem utilizados (obras), apenas trabaIhamos e o trabalhar é nosso produto" (ARTE EM REVISTA, 1981). O grupo fazia parte de um movimento chamado de "arte independente", iniciado na década de 1970 por jovens artistas em busca de autossuficiência e liberdade para criação'.

As ações dos coletivos de arte independente foram disruptivas, elas misturaram diversas linguagens artísticas em busca de expressões livres, capazes de fundir a arte aos novos comportamentos fora dos padrões de

1. Aqui não há espaço para tratar de forma mais detalhada do Viajou Sem Passaporte e demais coletivos de arte independente, no entanto, os leitores interessados podem ver minha dissertação de mestrado (BERTUCCI, 2015) ou os artigos que constam na bibliografia. 
coerência dos discursos contestadores da crítica militante e dos programas estéticos. Utilizo aqui o termo “ação disruptiva” (ARAÚJO, 2011) com base no artigo de Antônio Araújo, pois acredito que a sua metodologia - de categorizar ações corporais, inter-relacionais, contextuais e coletivas capazes de "provocar ruídos, estranhamentos ou falhas em lugares públicos, revelando contradições no espaço e/ou contradições do espaço" (Ibid., p. 2) - facilita o entendimento das relações entre os procedimentos performáticos e o espaço urbano. Além disso, faço algumas conexões entre esse conceito e o de "site specific art"intervencionista da crítica de arte coreano-americana Miwon Kwon.

Miwon Kwon defende que com o impulso do minimalismo, por volta do final da década de 1960 e início da seguinte, a arte foi deslocada dos museus e instituições artísticas para o espaço da cidade em dois modelos diferentes: o "assimilativo", em que o trabalho de arte tinha a intensão de se integrar ao ambiente existente e produzir um espaço unificado e harmonioso que "costumavam implicar algo enraizado, atrelado às leis da física" (KWON, 2008, p. 167); ao contrário, o modelo "intervencionista" funcionou como uma intervenção crítica na ordem existente do local, pois o objeto ou evento de arte teria que ser experimentado singularmente "no aqui-e-agora pela presença corporal de cada espectador, em imediatidade sensorial da extensão espacial e duração temporal, mais do que instantaneamente percebido em epifania visual por um olho sem corpo" (Ibid., p. 167).

O Evento Fim de Década foi uma ação urbana intervencionista, pois o Viajou Sem Passaporte pretendia instaurar um momento de liberdade para a criatividade dos habitantes da cidade em um contexto ditatorial, de forma coletiva com os demais independentes. Além disso, a intervenção desestabilizou a relação funcionalista e de uso cotidiano do espaço, quando a população voltava às ruas da cidade em decorrência da derrocada de poder da ditadura militar, com o fim do chamado "milagre econômico".

O Golpe Militar aconteceu no Brasil em primeiro de abril de 1964, após o presidente João Goulart ser deposto, e os militares permaneceram durante 21 anos no poder, período em que implantaram diretrizes adversas e violentas, entre elas, os Atos Institucionais; o Al-5 (1968-1978) foi o último e mais duro, com a substituição da Constituição de 1946 pela de 1967 e a dissolução do Congresso Nacional. No campo econômico, o país se tornou atraente para o 
capital monopolista - aberto aos laços da dependência financeira internacional para o entusiasmo das classes dominantes nacionais - nesse clima de ufanismo, elas se aproveitaram das sobras do milagre econômico, para ampliar o seu consumo. Não só as mercadorias (automóveis, televisores, apartamentos de veraneio), mas as artes também entraram para esse rol. Com isso, as artes plásticas sofreram um boom de mercado (com os leilões e a bolsa de arte determinando sua produção) e o teatro "empresarial" se voltou para as superproduções. Ou seja, a cultura de massa se transformou em um ótimo negócio e perdeu grande parte da vitalidade crítica. Tanto que, o Estado, que até então não fornecia opções para a produção artística, passou a definir uma política cultural e a tornar-se o maior patrocinador das exigências do mercado. Isso explica a adequação de artistas e intelectuais, em atuação desde os anos 1960, especialmente no cinema (HOLLANDA, 2004, p. 102).

Para romper com este cotidiano, os independentes buscaram outro modo de fazer arte e também de conviver politicamente, como pode ser observado no primeiro pré-evento organizado por eles, a Passeata Alfabética (1979), logo após a reunião no atelier do Viajou Sem Passaporte, com o intuito de angariar recursos para o evento da Praça da Sé. Os artistas atravessaram o centro velho de São Paulo carregando cartazes com letras sem nenhuma mensagem ou solicitação explícita e foram até a Secretaria Municipal de Cultura, onde exigiram uma reunião com o então secretário Mario Chamie²; eles defendiam que a arte e a cultura eram necessidades sociais. Hoje em dia essa solução parece óbvia, mas a Passeata Alfabética foi uma das primeiras vezes que um grupo de artistas se organizou para exigir do Estado a subvenção de seu trabalho (FIM..., 1979).

Não faz muito tempo, percebe-se nesta cidade que uma nova geração de artistas vem se formando, produzindo, reunindo-se e repensando muitas coisas a respeito da situação cultural do país. Uma boa parte dessa geração

2. O poeta com formação em Direito pela Faculdade de Direito do Largo São Francisco Mario Chamie (1933-2011) foi secretário de cultura da cidade de São Paulo na gestão de Reynaldo Emídio de Barros (1979-1983). Dentre as várias ações realizadas em seu secretariado, destaca-se a construção do Centro Cultural São Paulo, em 1983, segundo ele para abrigar em um só espaço cultura popular e erudita e todo tipo de manifestação cultural de grupos ou comunidades as mais diversas, para refletir "toda essa igualdade cultural brasileira que é feita justamente das diferenças" (Disponível em: <http://www.centrocultural.sp.gov. br/CCSP_historico.html>. Acesso em: 28 mar. 2016). 
não se satisfaz em simplesmente reproduzir o que foi feito nesses últimos dez anos e não se contenta em trilhar conformadamente o velho caminho das galerias, teatros, salas de concerto, editoras, "bocas de cinema", etc...; enfim, não lhe agrada a situação que há tanto tempo vem se repetindo, com as produções atomizadas, com a inexistência de debate, com a falta de questionamento que quase paralisa o meio artístico. (VIAJOU SEM PASSAPORTE et al., 1979, p. 1)

Figura 1 - Passeata Alfabética, Evento Fim de Década, 27.09.1979

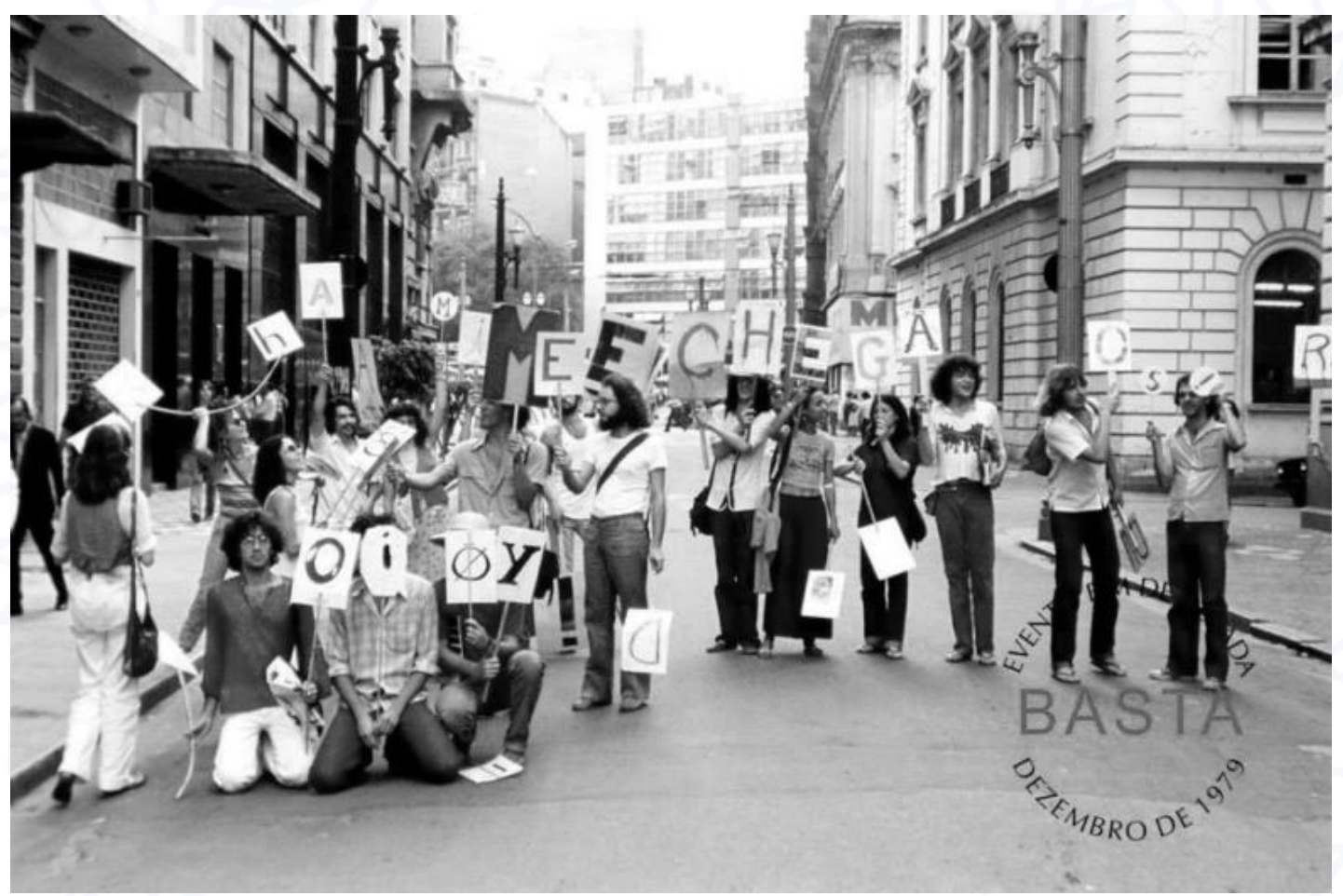

Fonte: Arquivo Viajou Sem Passaporte.

Outro pré-evento que chamou a atenção do público e da imprensa aconteceu dia 03 de outubro de 1979, na inauguração da XV Bienal Internacional de São Paulo. Os artistas caminharam em grupo, amarrados e com olhos vendados, por toda a Bienal, gritando: "oh! Maravilhoso, espetacular, brilhante". Ao sair, deixaram pequenos papéis nos quais se lia: "estive no fim de década basta! - s.p. 13 de dezembro - pça. da sé” (XV BIENAL..., 1979). 
Figura 2 - Pré-evento na Bienal, Evento Fim de Década

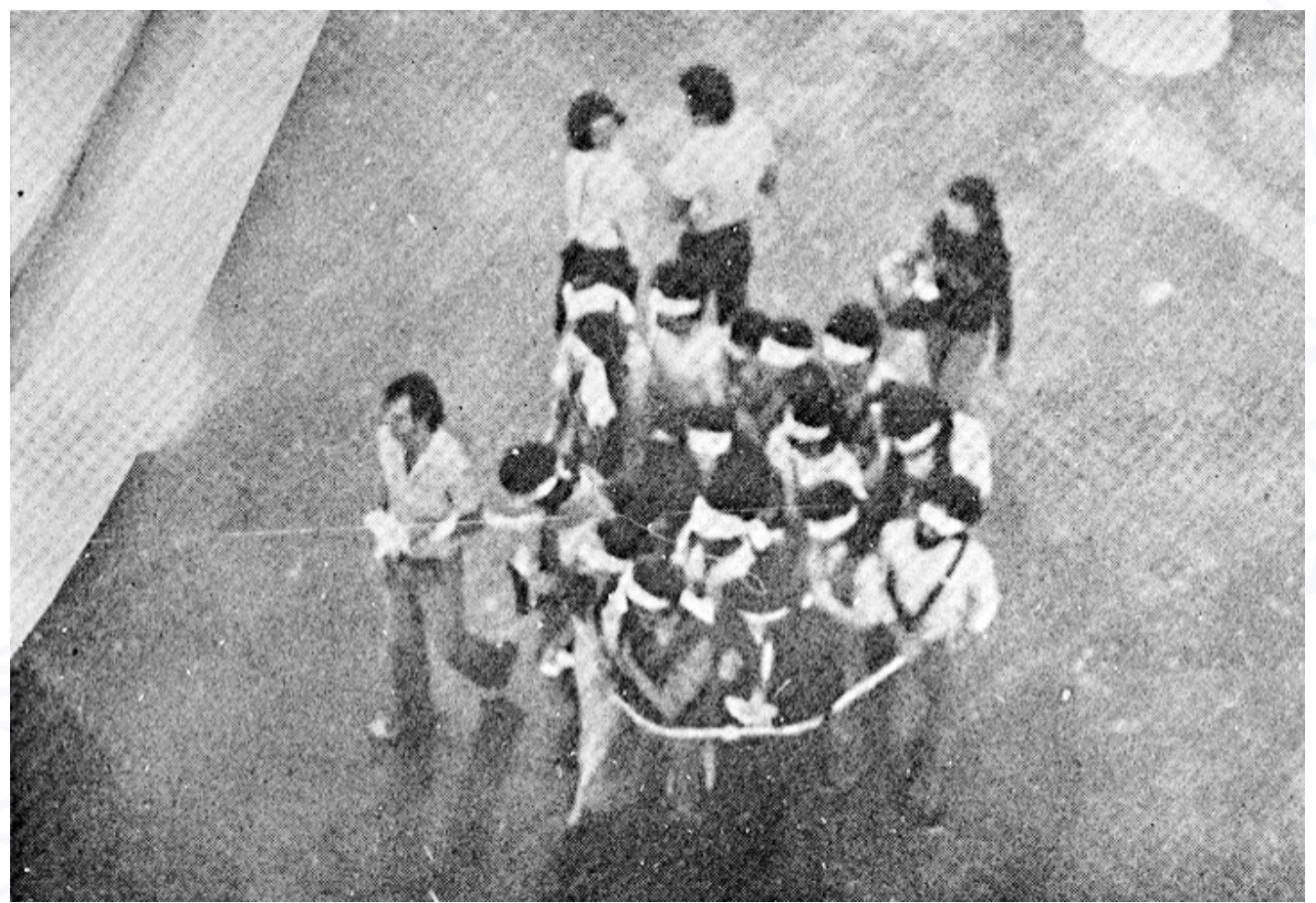

Fonte: Arquivo Viajou Sem Passaporte

Em seguida, eles intervieram no metrô. Como nos informou Roberto Melo do Viajou Sem Passaporte, o pré-evento consistiu em pedir ao público para carimbar um papel em branco. Os artistas entregavam o papel nas catracas do metrô e falavam para que ele fosse carimbado na saída. As pessoas pegavam o papel, ficavam olhando com desconfiança, mas a maioria levava no guichê dos artistas que carimbavam "estive no fim de década, basta!". A ação permaneceu apenas até a chegada do segurança do metrô, que expulsou todos: "A gente achava que isso era genial, e que íamos levar público para o evento na Praça da Sé! Mas na verdade ninguém entendia nada!" (informação verbal ${ }^{3}$ ).

O pré-evento Páginas escolhidas foi na Praça da Sé, onde os organizadores soltaram panfletos de divulgação para a ação final em dezembro. $\mathrm{Na}$ intervenção foram lidos pelos artistas trechos de diferentes livros, depois eles terminaram amarrados em volta do marco zero e reprimidos pela polícia. O penúltimo pré-evento ocorreu em cinco de novembro, na inaugura-

3. Entrevista para esta pesquisadora de Roberto Melo, membro do Viajou sem Passaporte, em 27 de agosto de 2013. 
ção da exposição Multimídia internacional ${ }^{4}$, e o último deles aconteceu em forma de passeata, no centro da cidade, no dia nove de novembro, em que os participantes se cobriram "com cartolinas contendo estranhos sinais, tal como homens-sanduíches de um hospício" (VIAJOU SEM PASSAPORTE et al., 1979, p. 1).

Portanto, os pré-eventos foram jogos lúdicos, chamados de irracionais pela crítica, mas, ao contrário, surgiram como um momento de reapropriação do espaço urbano em que os artistas quiseram abrir uma fissura nas possibilidades políticas. De acordo com o filósofo francês Jacques Rancière, a arte, "bem antes de ser o exercício de um poder ou uma luta pelo poder, é o recorte de um espaço específico de 'ocupações comuns'; é o conflito para determinar os objetos que fazem ou não parte dessas ocupações, os sujeitos que participam ou não delas, etc." (RANCIÈRE, 2005, p. 3).

Se a arte é política, ela o é enquanto os espaços e os tempos que ela recorta e as formas de ocupação desses tempos e espaços que ela determina interferem com o recorte dos espaços e dos tempos, dos sujeitos e dos objetos, do privado e do público, das competências e das incompetências, que define uma comunidade política. (loc. cit.)

Assim foi o Evento Fim de Década que, finalmente, após os três meses de pré-eventos, aconteceu no dia 13 de dezembro de 1979, aberto por um dragão chinês que seguiu em forma de bloco carnavalesco, engolindo e conquistando participantes desde o Teatro Municipal, até chegar ao ponto de encontro na Praça da Sé. O evento foi organizado pelos coletivos de artistas independentes em um formato que eles denominaram de "bases de ação". Essas bases ficavam espalhadas por toda a praça e funcionavam com um artista responsável por propor ações criativas a serem manipuladas pelo público. No entanto, nas bases, os artistas se colocavam apenas como organizadores, com a expectativa de que os expectadores se tornassem participadores.

Ou seja, as bases de ação foram proposições inter-relacionais (ARAÚJO, 2011), pois geraram intercâmbios inesperados, naquele momento deter-

4. O pré-evento na inauguração da exposição Multimídia internacional está citado no catálogo do Evento Fim de Década, porém, não há nenhuma descrição sobre como ele aconteceu. 
minado, entre os performers e as pessoas que estavam em deslocamento pela praça. Ainda que o público tenha desconfiado do caráter artístico da ação, ela foi antes experimentada do que justificada, pois o objetivo era criar uma situação que não se configurava de forma nítida como ato artístico ou teatral.

Nas bases o público era convidado a criar a partir das proposições dos organizadores. Em algumas delas havia materiais disponíveis para manipulação e criação do público, como na "bexiga/ spray /fita crepe/ barbante", "Caixas de papelão", "Papel e tinta" e "Escultura de vento"; mas em outras, como na "Música, Dança e Representação", os transeuntes precisavam usar seus próprios corpos. Na base "Guichê de informações" um guichê de plástico foi instalado logo na saída do metrô, com um disco de informações para ser comandado pelos transeuntes. Na base "Arte-postal" a proposta era enviar pelo correio uma cópia de cartões postais da Praça da Sé (que formavam um quebra-cabeça e tinham o título de "espaço reservado") para artistas de outros estados e, depois, aguardar o postal-resposta chegar pelo correio com a manipulação/reformulação do material enviado. Também pelo correio foram enviadas as fotografias tiradas pelo público na base "Lambe-lambe". Na base "Cinema/Tenda de projeção" filmes independentes foram exibidos para o público, com a intenção de se diferenciar das salas convencionais, o tempo dos filmes era, por isso, indeterminado, os autores dos filmes podiam intervir a qualquer momento durante a projeção, e o público podia participar da montagem e sonorização de alguns filmes. Por fim, algumas bases que estimulavam a troca de objetos entre os participantes, sem nenhum intuito comercial, elas foram "Barganha e souvenir" e "Troca simbólica" 
Figura 3 - Base dragão, Evento Fim de Década

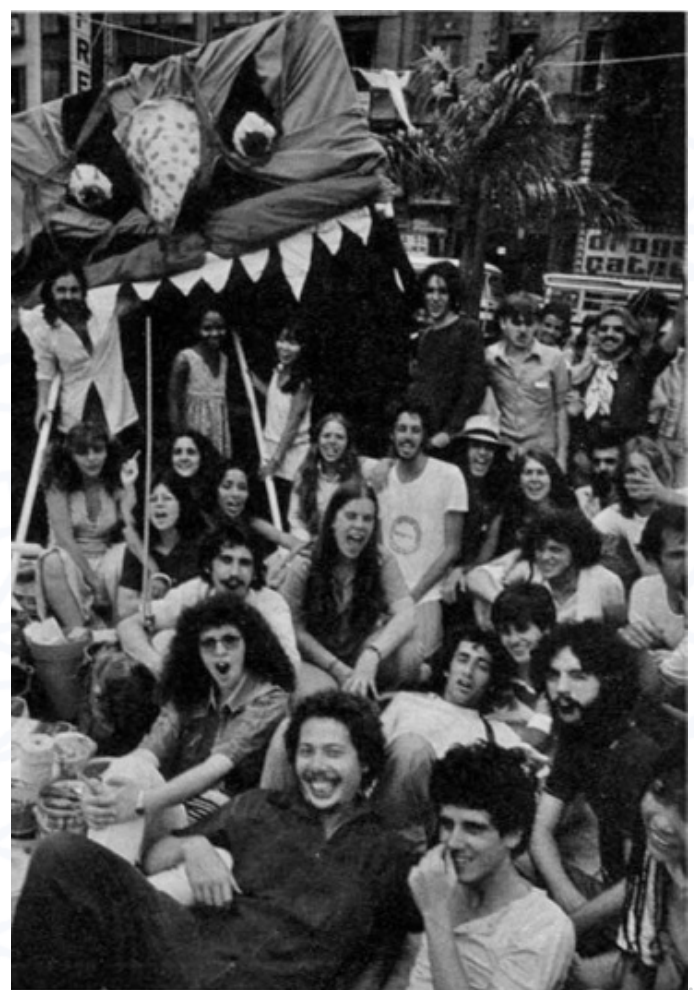

Fonte: Arquivo Viajou Sem Passaporte

Figura 4 - Base bexiga/spray/fita crepe/ barbante, Evento Fim de Década

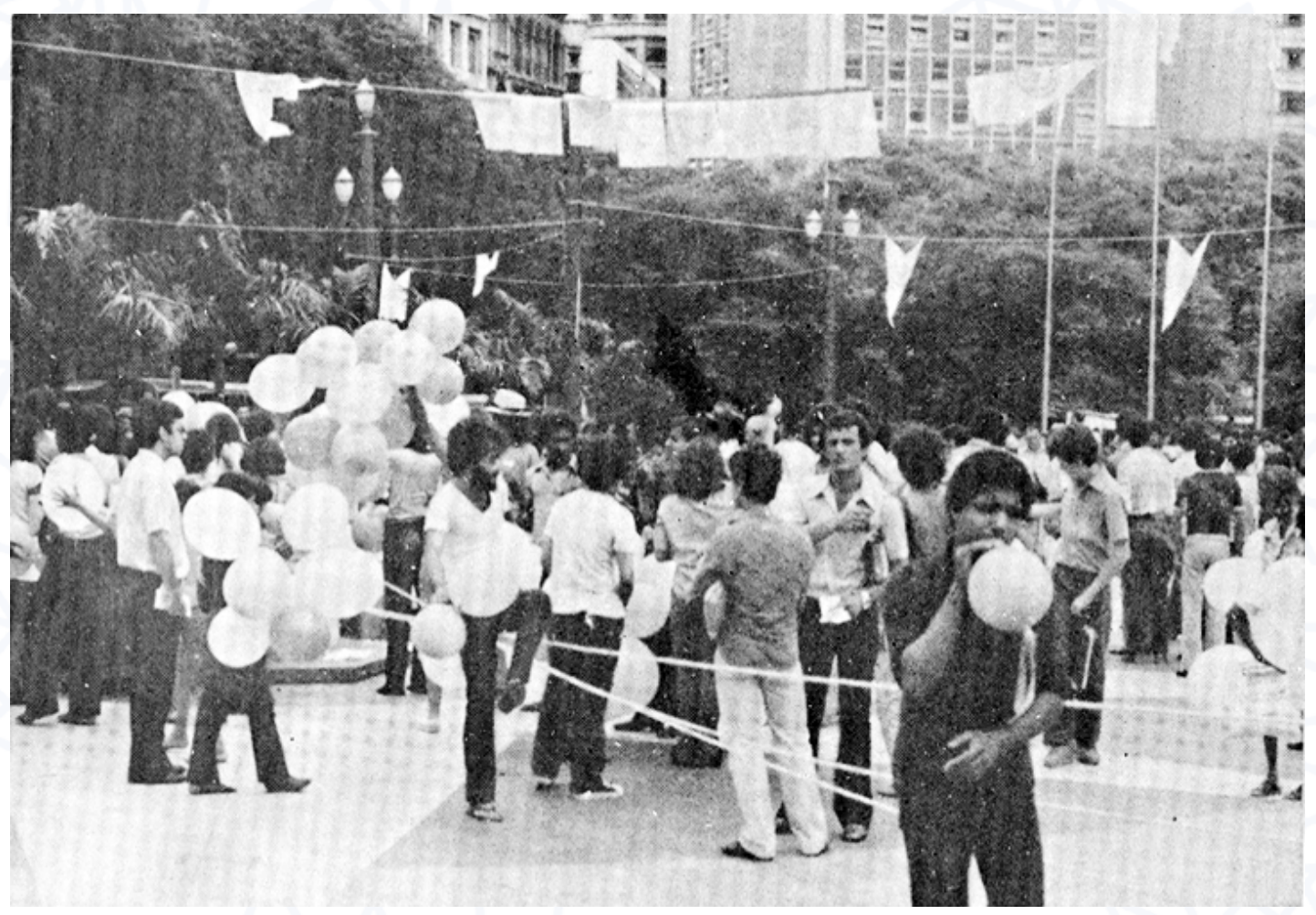

Fonte: arquivo Viajou Sem Passaporte 
Como fica claro nas descrições, as bases de ação não visaram ações autorais de artistas, mas propostas de situações para os espectadores, performances alinhadas à chamada "virada performativa" (FISCHER-LICHTE, 1997), que se intensificou na década de 1960. A pesquisadora alemã Fischer-Lichte usa esse termo para definir ações que trouxeram à tona inovações estéticas e ideológicas do teatro para colocar os corpos dos artistas e do público no centro de reflexão/ação da obra de arte, como foi proposto nas bases da ação do Evento Fim de Década.

A co-presença performer-espectador constituiu as situações do Evento Fim de Década, por meio de ações fugazes das quais ambos participam como autores num espaço real, num tempo real e com seus corpos reais. Afinal, durante as situações propostas, por meio da linguagem, os habitantes da cidade receberam informações capazes de despertar as seguintes tensões: a primeira se refere às categorias de sujeito que observa ilesamente (público) e o objeto de arte (obra), que tendem a se diluir à medida que o público é impelido a ser coautor da obra, e aquele que é o objeto a ser observado é o próprio artista, seu "corpo real"; a segunda tensão se dá entre "materialidade" e "semioticidade" no contexto de uma performance, ou seja, na superposição dos elementos materiais que compõem a cena e os atos reais infligidos pelo artista (signos e símbolos usados). As duas camadas convivem no instante da performance e disputam constantemente a percepção da audiência, materialidades que transformam seus usos (de funcionais para lúdicos) com o ato artístico.

Consequentemente, na estética do performativo, todo elemento de uma ação, por mais despretensiosa que possa parecer, torna-se signo diante do olhar do público. O que nos leva a pensar na produção do espaço urbano, potente no caso do evento, já que a intervenção se sobrepôs à reforma funcional e autoritária do governo militar ao propor o uso lúdico daquele espaço urbano específico. O contexto urbano de São Paulo refletia como um espelho a violência do regime, com as torturas, a censura e os desfiles militares; e também pelas grandes obras de engenharia e infraestrutura urbana, que priorizavam as rodovias para automóveis; foram construídos entre 1969 e 1973 as avenidas 23 de Maio e Radial Leste, a ligação Leste-Oeste (Minhocão, praça Roosevelt e viaduto Jaceguai), as alças e viadutos sobre o Parque D. Pedro II, 
as marginais dos rios Tietê e Pinheiros, as obras do metrô Sé com a revitalização da praça onde ele se situava e o projeto, parcialmente implantado, Nova Paulista. Esses investimentos em infraestrutura até poderiam ser necessários a uma parcela da população, mas não foram planejados tendo em vista um contexto social igualitário (BRESSER-PEREIRA, 2003).

A reforma da Praça da Sé foi inaugurada em janeiro de 1979, no 425은 aniversário de São Paulo, pelo prefeito Olavo Setúbal ${ }^{5}$. A obra inseriu desníveis e canteiros dispersos na praça, além de quatorze esculturas selecionadas por uma comissão instituída pela Emurb, que considerou o local "como um suporte único, tendo em vista critérios essenciais para a implantação de trabalhos numa situação urbana peculiar" (ARTE..., 1979). Porém, conforme Mario Ramiro, do 3 Nós $^{6}$, coletivo que colaborou na organização do Evento Fim de Década, a tal "situação urbana peculiar" era a de que a população utilizava a Praça da Sé como ponto de encontro para mobilização. Logo, um espaço ativo foi transformado em espaço passivo pelas obras e também pelas esculturas de arte colocadas no local. Além disso, o chamado "museu a céu aberto" de Setúbal foi bastante criticado pela população, como podemos ler nos jornais da época.

Já para o crítico de arte Odon Pereira, a reforma da praça seguia "o estilo de Brasília, incorporado à vida dos brasileiros, após 18 anos de sua inauguração" (loc. cit.). Tal comparação não deixa de ser interessante, pois sabemos que na década de 1970 o estilo moderno e sua visão funcionalista da cidade estavam em plena derrocada; a demolição realizada em 1972 do conjunto habitacional Pruitt-Igoe, construído pelo arquiteto Minoru Yamasaki

5. Olavo Egídio de Sousa Aranha Setúbal (1923-2008) foi engenheiro e empresário, fundador da empresa de louças sanitárias Deca e um dos maiores acionistas do banco Itaú. Prefeito da cidade de São Paulo entre 1975 e 1979, período em que criou a Empresa Municipal de Urbanização (Emurb) para realização de diversas obras urbanas de grande porte. Com a reforma pluripartidária de 1980, fundou, ao lado de Tancredo Neves, o Partido Popular, reunindo setores moderados egressos da Arena e do MDB. O partido, entretanto, teve vida curta, sendo logo incorporado pelo PMDB. Em 1985, foi um dos principais financiadores da campanha de Jânio Quadros à prefeitura de São Paulo.

6. O coletivo de arte independente 3 Nós3, formado por Mario Ramiro, Hudinilson Junior e Rafael França, realizava intervenções nas cidades para inverter a ordem e o fluxo natural dos espaços públicos. Assim como o Viajou Sem Passaporte, também nasceram dentro da Escola de Comunicações e Artes da Universidade de São Paulo, atuando de 1979 até 1982. Para obter mais informações sobre o coletivo ver minha dissertação de mestrado (BERTUCCI, 2015) ou os artigos que constam na bibliografia. 
em 1954, nos Estados Unidos, é reconhecida como um marco do fracasso da concepção modernista e da crise do ideário moderno, seus habitantes tinham tamanho repúdio pelo local, que celebraram a demolição tanto quanto sua inauguração ${ }^{7}$.

Portanto, com as bases de ação, propondo justamente o contrário desse ideal, os coletivos de artistas independentes destruíram as fronteiras entre "os 'próprios' das diferentes artes, ou a separação de um domínio puro da arte" (RANCIÈRE, 2005, p. 41). Com atos estéticos que se configuraram como experiência de partilha do sensível, eles levaram os participantes a novas formas de sentir o espaço público e, por conseguinte, a novas formas de subjetividade política. Esse conceito do filósofo francês Jacques Rancière descreve a formação da comunidade política com base no encontro discordante das percepções individuais.

Para Rancière, política e arte têm uma origem comum: a política é essencialmente estética, pois está fundada sobre o mundo sensível, assim como a arte. Logo, a democracia só se efetiva ao incentivar a multiplicidade de manifestações dentro das comunidades, por isso o valor simbólico do Evento Fim de Década, onde a ideia principal dos organizadores era estimular a criação anônima e coletiva, em um ato poético de retomada da Praça da Sé pela população, num período de redemocratização.

Passados mais de três décadas do fim do regime militar, será que, de fato, nos tornamos espectadores emancipados e apropriados da produção dos espaços públicos da cidade? Sem dúvida, ainda nos resta muito trabalho. Entretanto, os coletivos de arte independente do fim da década de 1970, com seus jogos de criatividade, estimularam corpos e mentes em busca de desvios momentâneos, decisivos e reveladores da totalidade de possibilidades contidas na existência diária.

7. Vale lembrar que o modernismo alimentava grandes esperanças quanto às possibilidades de transformar a sociedade, mediante a união entre tecnologia e estética, em escala fabril, possibilitando assim a produção de utensílios e moradia em grande escala, para toda população. Sua teoria estava baseada em uma fé ilimitada na contribuição das revoluções científica e industrial para o bem-estar da humanidade. 


\section{Referencias bibliográficas}

ARAÚJO, Antônio. Ações Disruptivas no Espaço Urbano. In: VI Reunião Científica da ABRACE, 2011, Porto Alegre, RS. Memória ABRACE Digital - Anais da VI Reunião Científica da ABRACE. Porto Alegre, RS, 2011. p. 1-6.

ARTE EM REVISTA, São Paulo, v. 3, n. 5, 1981, p. 102.

ARTE EM REVISTA, São Paulo, v. 6, n. 8, 1984, p. 1-119.

ARTE na Sé, um presente que o povo já critica. Folha de S. Paulo, São Paulo, 25 jan. 1979 (Fonte: Arquivo Multimeios/CCSP).

BERTUCCI, P. M. Intervenção urbana, São Paulo (1978-1982): o espaço da cidade e os coletivos de arte independente Viajou Sem Passaporte e 3Nós3. 2015. Dissertação (Mestrado em Artes Cênicas) - Escola de Comunicação e Artes, Universidade de São Paulo, São Paulo, 2015. Disponível em: <http://www.teses.usp.br/ teses/disponiveis/27/27156/tde-14012016-104059/>.

BRESSER-PEREIRA, L. C. Desenvolvimento e crise no Brasil. São Paulo: Editora 34, 2003.

DE CERTEAU, M. A invenção do cotidiano: 1. artes de fazer. Rio de Janeiro: Vozes, 2013.

FIM de Década na Praça da Sé. Folha de S. Paulo, São Paulo, 9 out. 1979, ilustrada, p.64 (Fonte: Arquivo Multimeios/CCSP).

FISCHER-LICHTE, É. The show and the gaze of the theatre. lowa: lowa University Press, 1997.

The Transformative Power of Performance: a new aesthetics. New York: Routledge, 2008.

HOLLANDA, H. B. Impressões de viagem: CPC, vanguarda e desbunde: 1960/70.

Rio de Janeiro: Aeroplano, 2004.

KWON, M. One place after another: site-specificity art and locational identity. Cambridge: The MIT Press, 2004.

LEFEBVRE, H. The production of space. Oxford: Blackwell Publishers, 1991.

LÓPEZ, M. et al. Perder la forma humana: una imagen sístimica de los años ochenta en América Latina. Madri: Museu Nacional Centro de Arte Reina Sofía, 2012. (Catálogo de exposição artística).

PROJETO "Fim de Década" leva as artes à praça. O Estado de São Paulo, São Paulo, 12 dez. 1979, p.22 (Fonte: Arquivo Multimeios/CCSP).

RANCIÈRE, J. O espectador emancipado. São Paulo: WMF Martins Fontes, 2012. RANCIERE, Jacques. Política da Arte, transcrição do seminário "São Paulo S.A, práticas estéticas, sociais e políticas em debate" (São Paulo, SESC Belenzinho, 17 a 19 de abril de 2005). Disponível em: <http://www.sescsp.org.br/sesc/images/ upload/conferencias/206.rtf>. 
VIAJOU SEM PASSAPORTE et al. Top Secret: Evento Fim de Década: set. a dez. de 1979. São Paulo: ECA/USP, 1979. (Catálogo de intervenção artística).

XV BIENAL Internacional é aberta por Paulo Maluf. Folha de S. Paulo, São Paulo, 04 out. 1979, primeiro caderno, p.37 (Fonte: Arquivo Multimeios/CCSP).

Recebido em 23/02/2016

Aprovado em 03/05/2016

Publicado em 30/06/2016 